\title{
Megacity emission plume characteristics in summer and winter investigated by mobile aerosol and trace gas measurements: the Paris metropolitan area
}

\author{
S.-L. von der Weiden-Reinmüller et al.
}

Correspondence to: F. Drewnick (frank.drewnick@mpic.de) 


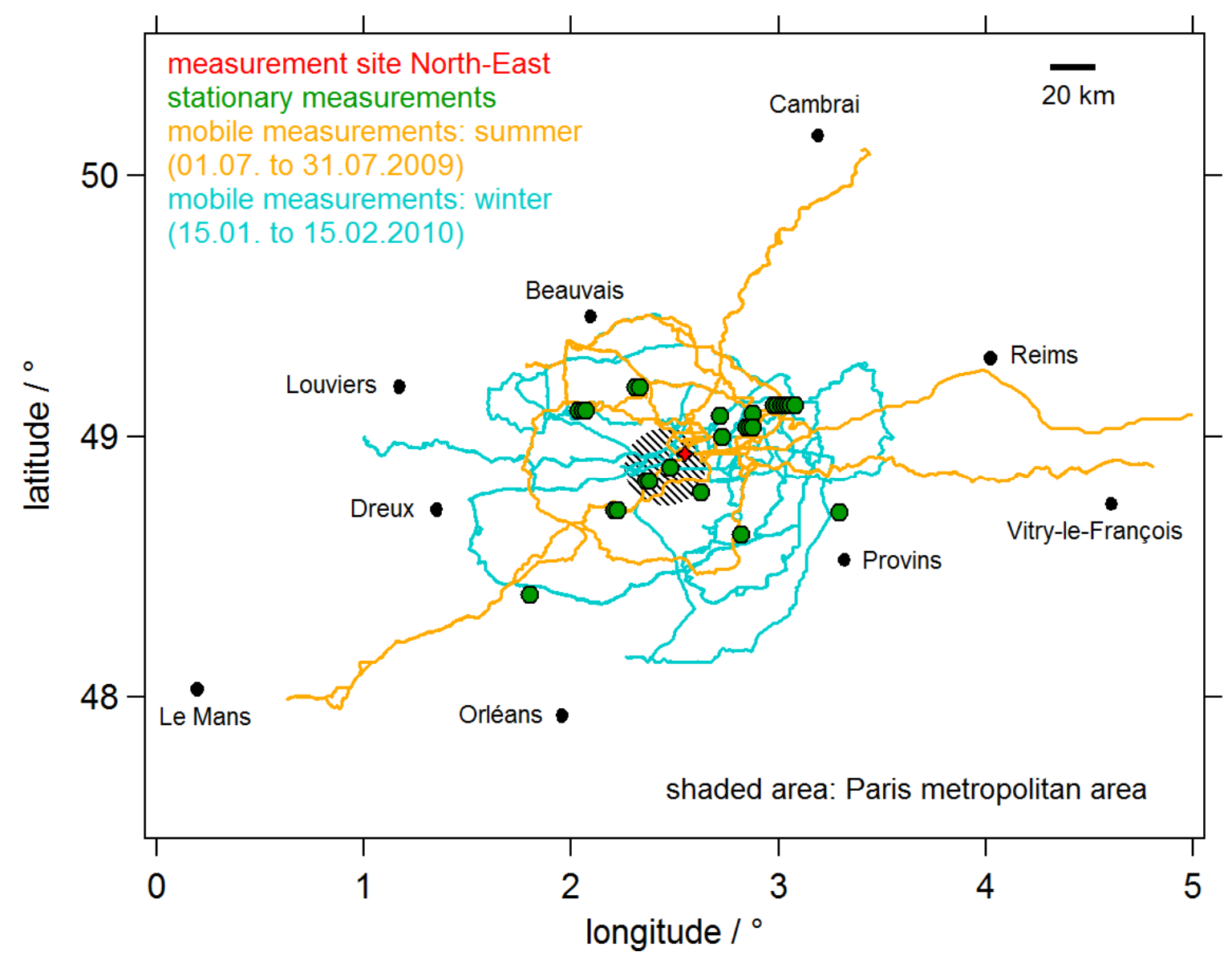

Figure S1. Overview of MoLa measurements during the MEGAPOLI summer and winter field campaigns. The red star shows the location of the fixed measurement site northeast of Paris (also MoLa parking place), the green circles show locations of stationary MoLa measurements, the orange lines represent the tracks of MoLa mobile measurements during the summer campaign and the blue lines represent the tracks of mobile measurements during the winter campaign. The hatched area symbolizes the Paris metropolitan area. 


\section{S1 PMF 5 factor solution of the MoLa MEGAPOLI summer data set}

The organic aerosol measured by MoLa during the MEGAPOLI summer field campaign is described best by the PMF solution with five factors. These factors are:

- HOA (Hydrocarbon-like Organic Aerosol): fresh pollution marker, associated with traffic emissions

- COA (Cooking-related Organic Aerosol): fresh pollution marker, associated with cooking emissions

- SV-OOA1 (Semi-Volatile Oxygenated Organic Aerosol): medium-aged pollution marker, associated with mixture of various sources including biomass burning

- SV-OOA2: medium-aged pollution marker, associated with mixture of various sources including secondary biogenic emitters

- LV-OOA (Low-Volatile Oxygenated Organic Aerosol): aged pollution marker, associated with long-range transported pollution.

For the identification of the factors of each solution correlations with time series of additional variables measured on-board MoLa were used. These include: $\mathrm{NO}_{\mathrm{x}}, \mathrm{CO}_{2}, \mathrm{SO}_{2}, \mathrm{O}_{3}$, black carbon, particle-bound $\mathrm{PAH}$, sub-micron particulate sulfate, nitrate, ammonium, and $\mathrm{O} / \mathrm{C}$ ratio. To calculate the coefficient of determination $R^{2}$ time series with about 36700 data points with 1 min temporal resolution were used. Additionally, the factors' mass spectra were compared to mass spectra from the AMS mass spectra database of source-related spectra, and PMF factors from other field campaigns (AMS Spectral Database, 2013), and additional mass spectra published in Allan et al. (2010) and He et al. (2010). The mass spectra used for the comparison included around 250 to $300 \mathrm{~m} / \mathrm{z}$. The comparison of time series and mass spectra of all five factors with each other show that the differences of these five factors are significant, in terms of temporal behavior as well as chemical composition. In the following the factors are described in more detail.

HOA: The HOA factor time series of the 5 factor solution correlates reasonably well (coefficient of determination $R^{2}$ of 0.5 to 0.6 ) with the time series of fresh pollutant markers $\left(\mathrm{NO}_{\mathrm{x}}\right.$, black carbon, particle-bound $\mathrm{PAH}, \mathrm{CO}_{2}$ and $\left.\mathrm{SO}_{2}\right)$. The correlation with long-range transported pollution markers (particulate sulfate, nitrate and ammonium) is negligible $\left(R^{2}<\right.$ 
0.1). This supports the assumption that this factor is associated with fresh pollution from sources like traffic and residential heating. Therefore, this factor should be a good marker to identify the Paris emission plume. There is high similarity $\left(R^{2}>0.9\right)$ between this factor mass spectrum and HOA mass spectra derived for other field campaigns. The good correlation $\left(R^{2}\right.$ $>0.8$ ) with laboratory mass spectra of fresh diesel exhaust, fuel and lubricating oil also suggests that this factor mainly contains organic aerosol related to traffic emissions. This is also supported by various sharp spikes (e.g., from single vehicles) in the raw time series (including the contaminated data points) of the HOA factor.

COA: The COA factor time series does not correlate with any of the measured time series mentioned above $\left(R^{2}<0.1\right)$. This is not surprising because none of the measured variables is dominated by cooking-related emissions. Comparison of this factor's average mass spectrum to mass spectra from cooking activities and COA factors derived for different field campaigns shows good correlation $\left(R^{2}>0.8\right)$. There is also very good agreement with laboratory mass spectra of oleic acid, which can be used as marker for cooking-related emissions (Schauer et al., 1996). The time series of the COA factor shows enhanced concentrations between 12:00 and 15:00 local time as well as strongly enhanced values after 21:00 local time. This corresponds to similar results found for this type of aerosol at the fixed measurement sites during both MEGAPOLI campaigns (Crippa et al., 2013; Freutel et al., 2013, Beekmann et al., 2014).

$S V$-OOA1: The SV-OOA1 factor time series shows some correlation $\left(R^{2}\right.$ between 0.3 and 0.4$)$ with time series of fresh pollution markers and no correlation $\left(R^{2}<0.1\right)$ with long-range transported pollution markers. The mass spectra correlations with factor mass spectra from other field campaigns associated with biomass burning are good ( $R^{2}$ around 0.6). The comparison to laboratory mass spectra of levoglucosan and source spectra of different burning substances show similar agreement. This factor seems to be associated with organic aerosol from different sources, while biomass burning-related organic aerosol is mixed into it. During summer biomass burning is not expected to be a major source of air pollution, because residential heating occurs much less than in winter. However, sporadic lop fires and barbecue activities can still release organic aerosol with biomass burning signature to the atmosphere. 
$S V$-OOA2: The SV-OOA2 factor time series correlates significantly only with the time series of $\mathrm{O}_{3}\left(R^{2}=0.3\right)$. This fits with the good correlation $\left(R^{2}>0.8\right)$ of the factor mass spectrum with laboratory mass spectra of secondary organic aerosol from oxidation of substances related to biogenic sources (e.g., of $\alpha$-humulene, $\alpha$-pinene, $\alpha$-terpinene and $\beta$-caryophyllene). $\mathrm{O}_{3}$ formation is also connected with the amount of available solar radiation and volatile organic compounds (VOCs). So this factor seems to represent mainly secondary organic aerosol from biogenic sources. South and southwest of Paris two natural parks ("Parc Naturel Régional du Gâtinais Français" and "Parc Naturel Régional de la Haute Vallée de Chevreuse") are located, which include both a large forested area. These forests could be potential sources of biogenic aerosol (see also Beekmann et al., 2014). Additionally, a contribution of anthropogenic VOCs emitted in the city to this factor is also possible.

LV-OOA: The LV-OOA factor time series shows some correlation ( $R^{2}$ from 0.2 to 0.4$)$ with long-range transported pollution markers and no correlation with fresh pollution markers' time series. This goes in line with good correlation $\left(R^{2}>0.6\right)$ of the mass spectrum of this factor with mass spectra associated with aged background air masses from different field campaigns. There is also very good correlation with laboratory mass spectra of substances with high $\mathrm{O} / \mathrm{C}$ ratios (e.g., oxalic acid). This supports the assumption that the LV-OOA represents the most aged part of the organic aerosol.

In Fig. S2 the mass spectra of these five factors are presented. Included is the $m / z, 44$ (mainly $\mathrm{CO}_{2}^{+}$) to total organics ratio, which is an approximation for the oxidation state and therewith a proxy for the age of the aerosol represented by the respective factor (Aiken et al., 2008). 

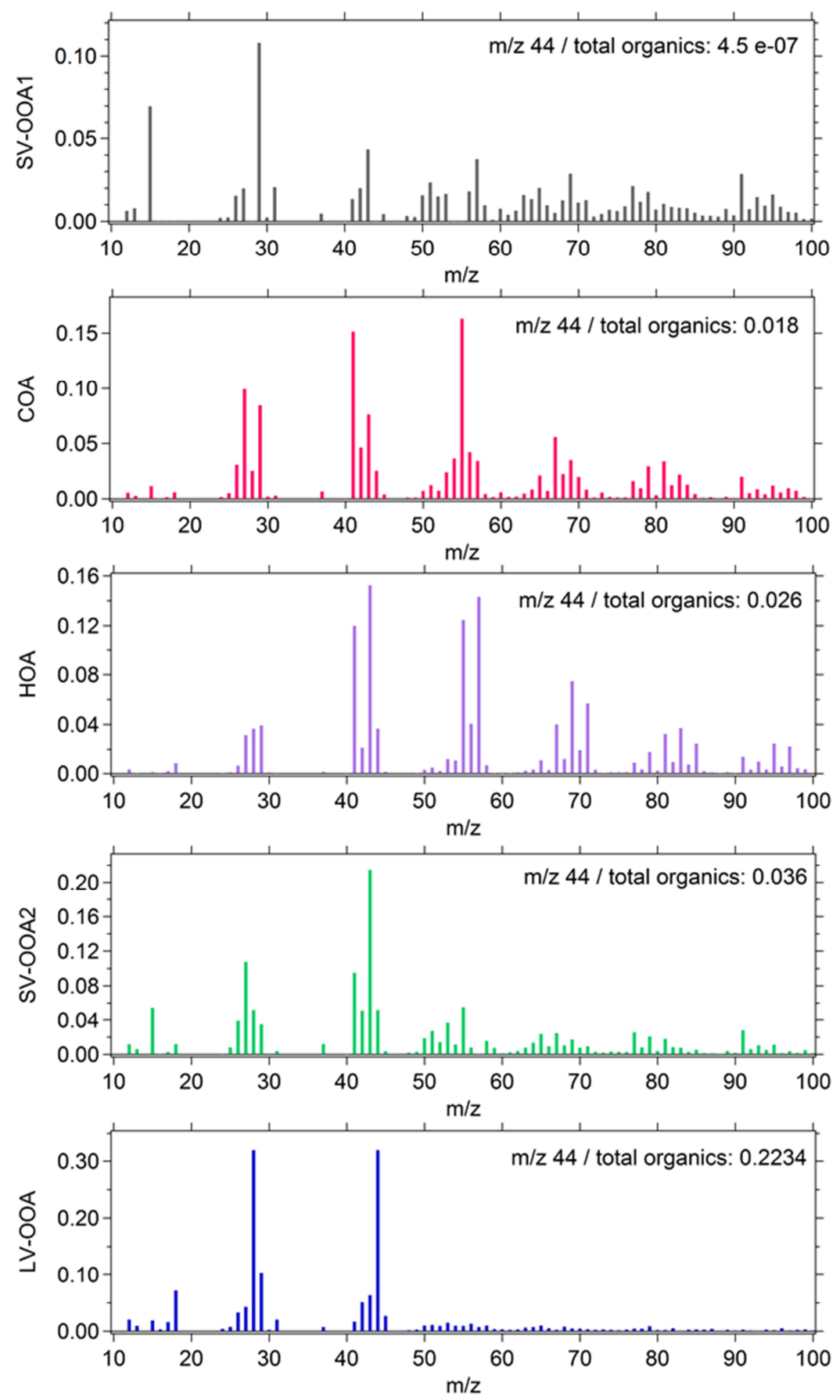

Figure S2. Mass spectra corresponding to the PMF 5 factor solution of the MEGAPOLI summer data set: SV-OOA1 (gray), COA (pink), HOA (purple), SV-OOA2 (green) and LV-OOA (blue). The $m / z, 44$ to total organics ratio is an approximation for the oxidation level of the respective organic aerosol fraction. 


\section{S2 PMF 3 and 6 factor solutions of the MoLa MEGAPOLI winter data set}

The organic aerosol measured by MoLa during the MEGAPOLI winter field campaign is described well by the PMF solutions with three and six factors. The 6 factor solution provides the most detailed view on the organic aerosol and was therefore used for further analysis. The factors of the 3 and 6 factor solutions are:

- HOA and COA: one common factor in 3 factor solution, subdivided in 6 factor solution; fresh pollution markers, associated with traffic and cooking emissions

- BBOA (Biomass Burning-related Organic Aerosol): one factor in 3 factor solution, subdivided into two factors (one fresh (BBOA2) and one more aged (BBOA1)) in 6 factor solution; fresh and medium-aged pollution markers, associated with biomass burning emissions

- OOA (Oxygenated Organic Aerosol): one factor in 3 factor solution, subdivided into two factors (one medium-aged (SV-OOA) and one highly-aged (LV-OOA)) in 6 factor solution; medium- and highly-aged pollution markers of various sources, LV-OOA associated with long-range transported pollution.

For the identification of the factors the same fresh and long-range transported pollution markers measured on-board MoLa (time series with about 42800 data points with a temporal resolution of $1 \mathrm{~min}$ ), and data base mass spectra (with about 250 to $300 \mathrm{~m} / \mathrm{z}$ ) as for the summer data set were used. The correlation of time series and mass spectra of all factors among each other for both PMF solutions shows that the difference between the respective factors is significant. Each factor can be assigned to a different type of aerosol associated with a certain oxidation level (age) and / or a specific source. In the following the factors are described in more detail.

HOA and COA: The HOA factor of the 3 factor solution correlates well with fresh pollution markers $\left(R^{2}\right.$ around 0.6$)$ and there is no significant correlation with long-range transported pollution markers $\left(R^{2} \leq 0.1\right)$. The temporal behavior of the HOA factor is dominated by sharp spikes in the raw concentration time series like during the summer campaign. This indicates that this factor can be associated with air masses containing fresh pollution (e.g., the Paris emission plume). The comparison with HOA mass spectra from other field campaigns shows 
very high similarity ( $R^{2}$ between 0.8 and 1.0). The good correlation with laboratory mass spectra of fresh diesel exhaust, fuel and lubricating oil shows a large influence of traffic emissions onto this factor. The correlation between the summer and the winter HOA factor mass spectra shows an $R^{2}$ of 1.0. There is also good correlation $\left(R^{2}\right.$ between 0.5 and 0.8$)$ of this factor with cooking-related mass spectra (from other field campaigns as well as laboratory studies). This supports the assumption that this factor can be subdivided into two factors in the 6 factor solution.

Consequently, in the 6 factor solution the combined HOA factor splits into one factor associated mainly with traffic emissions (HOA) and one factor associated with cooking activities (COA). The HOA factor time series shows again good correlation ( $R^{2}$ around 0.6) with the time series of fresh pollution markers and no similarity with the temporal behavior of the long-range transported pollution markers $\left(R^{2}<0.1\right)$. The mass spectrum shows the same high similarity, like for the 3 factor solution $\mathrm{HOA}$, with different $\mathrm{HOA}$ as well as diesel exhaust, fuel and lubricating oil mass spectra. The HOA factors of both solutions (3 and 6 factor solutions) are very similar $\left(R^{2}=1.0\right)$. The summer HOA and the winter 6 factor solution HOA are nearly identical $\left(R^{2}=1.0\right)$. The COA factor time series shows some correlation ( $R^{2}$ between 0.2 and 0.4 ) with the time series of fresh pollution markers and no significant correlation with the aged pollution markers $\left(R^{2}<0.2\right)$. The similarity with different COA mass spectra and marker substances is strong with $R^{2}$ around 0.8 . The comparison of the summer and winter COA factor mass spectra shows good agreement $\left(R^{2}=0.9\right)$. The temporal behavior of this factor time series is similar to that of the COA factor of the summer campaign. Enhanced cooking-related organic aerosol concentrations can be observed around noon and in the evening. However, during winter cooking activities in the evening seem to start earlier (from 19:00 local time) than during summer (from 21:00 local time), potentially because of earlier dinner times due to shorter daylight times.

BBOA: The BBOA factor time series of the 3 factor solution does not correlate significantly with any of the measured time series of other pollutants $\left(R^{2}<0.2\right)$. This is expected because none of the measured variables is dominated by biomass burning emissions. The mass spectra comparison shows good correlation $\left(R^{2}>0.7\right)$ with BBOA factors from other field campaigns and from laboratory studies measuring various burning substances. The correlation with 
levoglucosan mass spectra is medium to good with $R^{2}$ around 0.5 to 0.7 . The factor mass spectrum shows clear contribution of $m / z, 60\left(\mathrm{C}_{2} \mathrm{H}_{4} \mathrm{O}_{2}{ }^{+}\right)$and $73\left(\mathrm{C}_{3} \mathrm{H}_{5} \mathrm{O}_{2}{ }^{+}\right)$which are both markers for biomass burning-related organic aerosol (Schneider et al., 2006; Alfarra et al., 2007).

When separating the organic aerosol into six factors the combined BBOA factor splits into two biomass burning-related factors (BBOA1 and BBOA2) with different oxidation levels (ages). Both BBOA factors have clear $\mathrm{m} / \mathrm{z} 60$ and 73 contribution to their mass spectra. The BBOA2 factor time series shows some correlation $\left(R^{2}\right.$ around 0.2 to 0.3$)$ with the time series of black carbon and $\mathrm{CO}_{2}$, while the BBOA1 factor time series shows no correlation with any of the measured time series $\left(R^{2} \leq 0.1\right)$. This can be explained by the difference in age of these two factors. According to the $\mathrm{m} / \mathrm{z}, 44$ to total organics ratio, BBOA1 $(\mathrm{m} / \mathrm{z}, 44$ percentage of $7 \%)$ is approximately twice as much oxidized as BBOA2 $(\mathrm{m} / z, 44$ percentage of $4 \%)$. Both BBOA factor mass spectra correlate well with various biomass burning-related mass spectra. The BBOA1 factor correlates better with ambient biomass burning-related mass spectra $\left(R^{2}>\right.$ 0.7 , compared to $R^{2}$ mainly $<0.7$ for BBOA2; mainly more aged), while the BBOA2 factor shows higher similarity $\left(R^{2}>0.7\right.$, compared to $R^{2}$ mainly $<0.7$ for BBOA1) with laboratory mass spectra of very fresh emissions from biomass burning.

OOA: The OOA factor time series of the 3 factor solution correlates well ( $R^{2}$ around 0.6$)$ with time series of long-range transport pollution markers and there is no similarity with the temporal behavior of the fresh pollution markers $\left(R^{2}<0.1\right)$. The factor mass spectrum correlates best ( $R^{2}$ around 0.7$)$ with mass spectra that represent aged background organic aerosol during other field campaigns. Laboratory mass spectra from substances with high $\mathrm{O} / \mathrm{C}$ ratio have higher similarity with the OOA factor than those from substances with lower $\mathrm{O} / \mathrm{C}$ ratio. This shows that this factor mainly corresponds to the more aged organic aerosol measured during the campaign. The correlation with the summer LV-OOA factor is extremely $\operatorname{good}\left(R^{2}=1.0\right)$.

When calculating six factors the combined OOA factor splits into a less (SV-OOA) and a more oxidized (aged) fraction (LV-OOA). The SV-OOA factor time series has a good correlation $\left(R^{2}>0.7\right)$ with time series of medium-aged pollution markers (especially particulate nitrate, $\left.R^{2}=0.8\right)$ and no significant correlation with fresh pollution markers $\left(R^{2} \leq\right.$ 
$0.1)$. The factor mass spectrum correlates well $\left(R^{2}>0.7\right)$ with several other mass spectra related to medium-aged organic aerosol. The LV-OOA factor time series shows medium agreement ( $R^{2}$ around 0.4$)$ with those of long-range transport pollution markers (best correlation for particulate sulfate, $R^{2}=0.4$ ) and no correlation with fresh pollution markers $\left(R^{2}<0.1\right)$. According to the $\mathrm{m} / \mathrm{z}, 44$ to total organics ratio $(\mathrm{m} / \mathrm{z}, 44$ percentage of $25 \%$ of the total organics signal) this factor represents organic aerosol that is approximately twice as much oxidized as the organic aerosol corresponding to the SV-OOA factor $(\mathrm{m} / \mathrm{z}, 44$ percentage of $13 \%$ ). Correlation with other mass spectra shows good agreement ( $R^{2}$ from 0.6 to 0.8 ) with other aged organic background aerosol mass spectra and very good agreement $\left(R^{2}>0.8\right)$ with laboratory mass spectra of substances with high $\mathrm{O} / \mathrm{C}$ ratio. The similarity with the summer LV-OOA factor is very strong $\left(R^{2}=1.0\right)$.

In Fig. S3 the mass spectra of both solutions' factors including the respective $m / z$, 44 to total organics ratios are presented. 

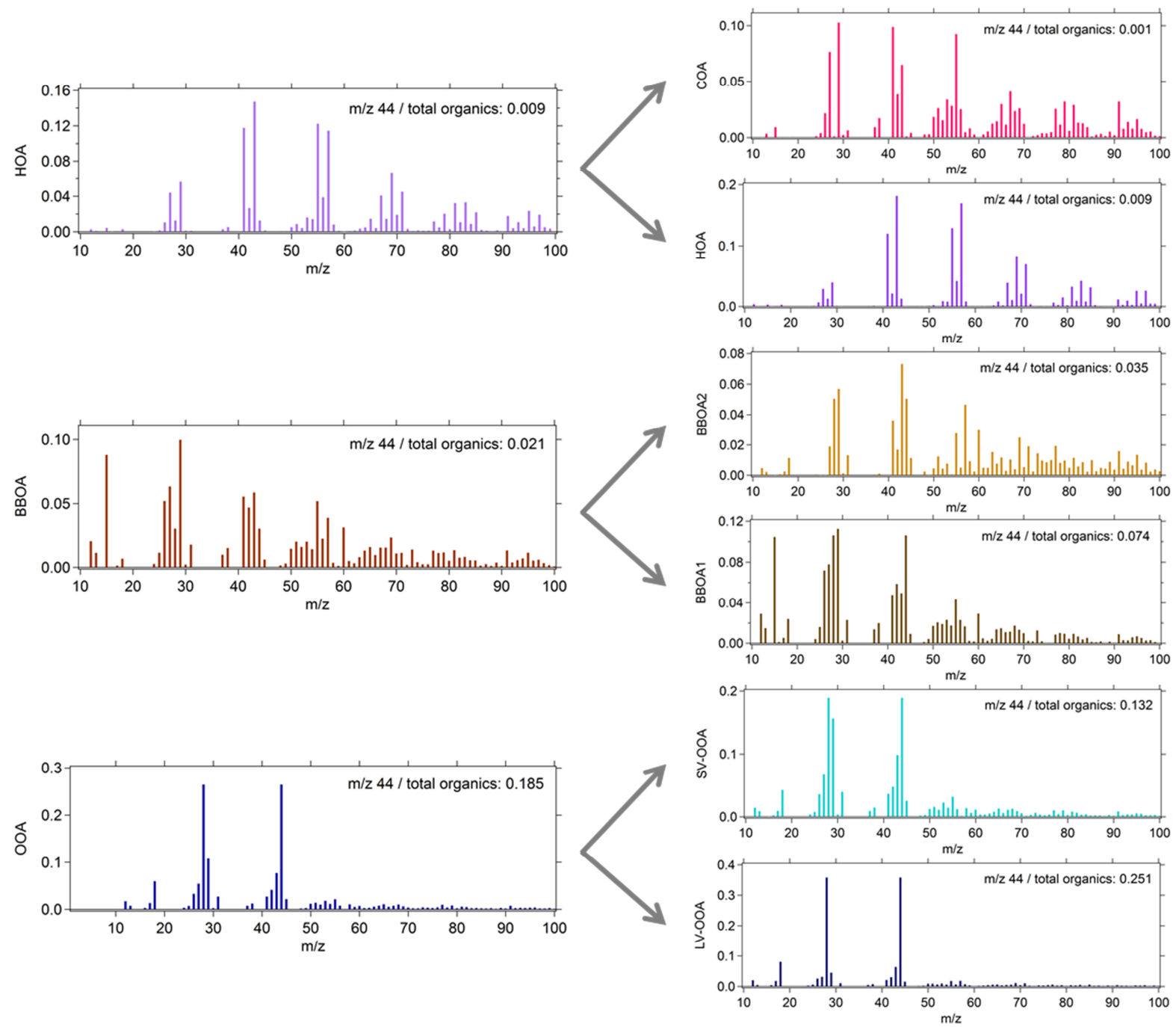

Figure S3. Mass spectra corresponding to the PMF 3 factor solution of the MEGAPOLI winter data set (left-hand side): HOA (light purple), BBOA (medium brown) and OOA (medium blue), and the 6 factor solution (right-hand side): COA (pink), HOA (medium purple), BBOA2 (light brown), BBOA1 (dark brown), SV-OOA (light blue) and LV-OOA (dark blue). The arrows demonstrate the separation of the corresponding PMF factors when increasing the number of factors from three to six. The $\mathrm{m} / \mathrm{z} 44$ to total organics ratio is an approximation for the oxidation level of the respective organic aerosol fraction. 

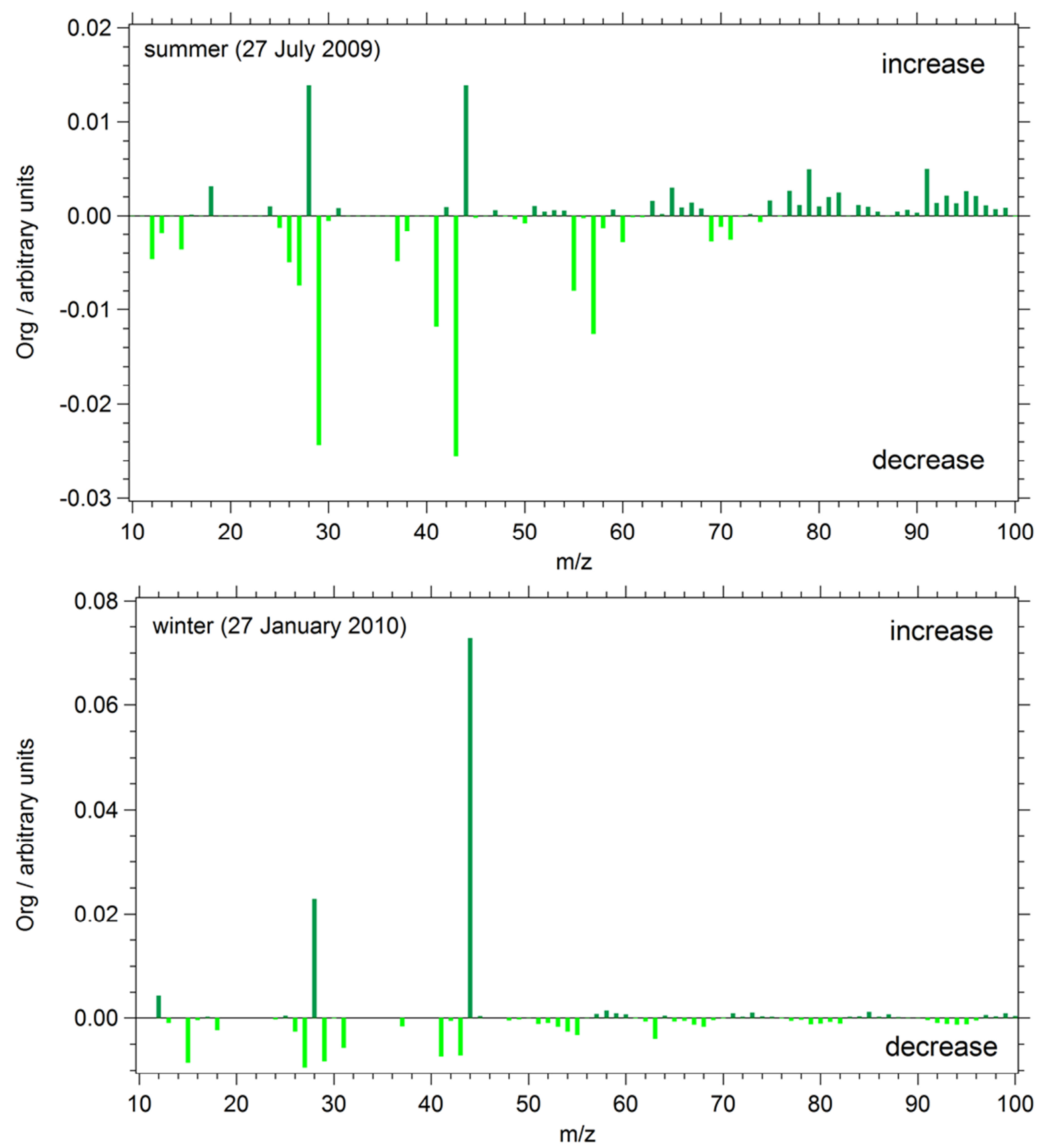

Figure S4. Changes in the average organic mass spectrum during aerosol transport in the advected Paris emission plume. The mass spectra were obtained from two simultaneous measurements (27 July 2009 and 27 January 2010) at the fixed suburban northeastern measurement site (Freutel et al., 2013) and downwind stationary MoLa measurements northeastern of Paris about $30 \mathrm{~km}$ outside the agglomeration. The decrease and increase parts 
of the mass spectra were correlated separately with the respective PMF mass spectra of the MoLa summer and winter data sets to obtain information about the changes in organic aerosol during transport. 
S3 Homogeneity and spatial distribution of pollutants in the emission plume - more measurement examples

Here we present five more measurement examples showing the Gaussian-like profile of cross sections through the emission plume and the exponential axial decrease of fresh pollution concentrations inside the emission plume. Additionally, we show the corresponding model data based on the CHIMERE model (Zhang et al., 2013). 


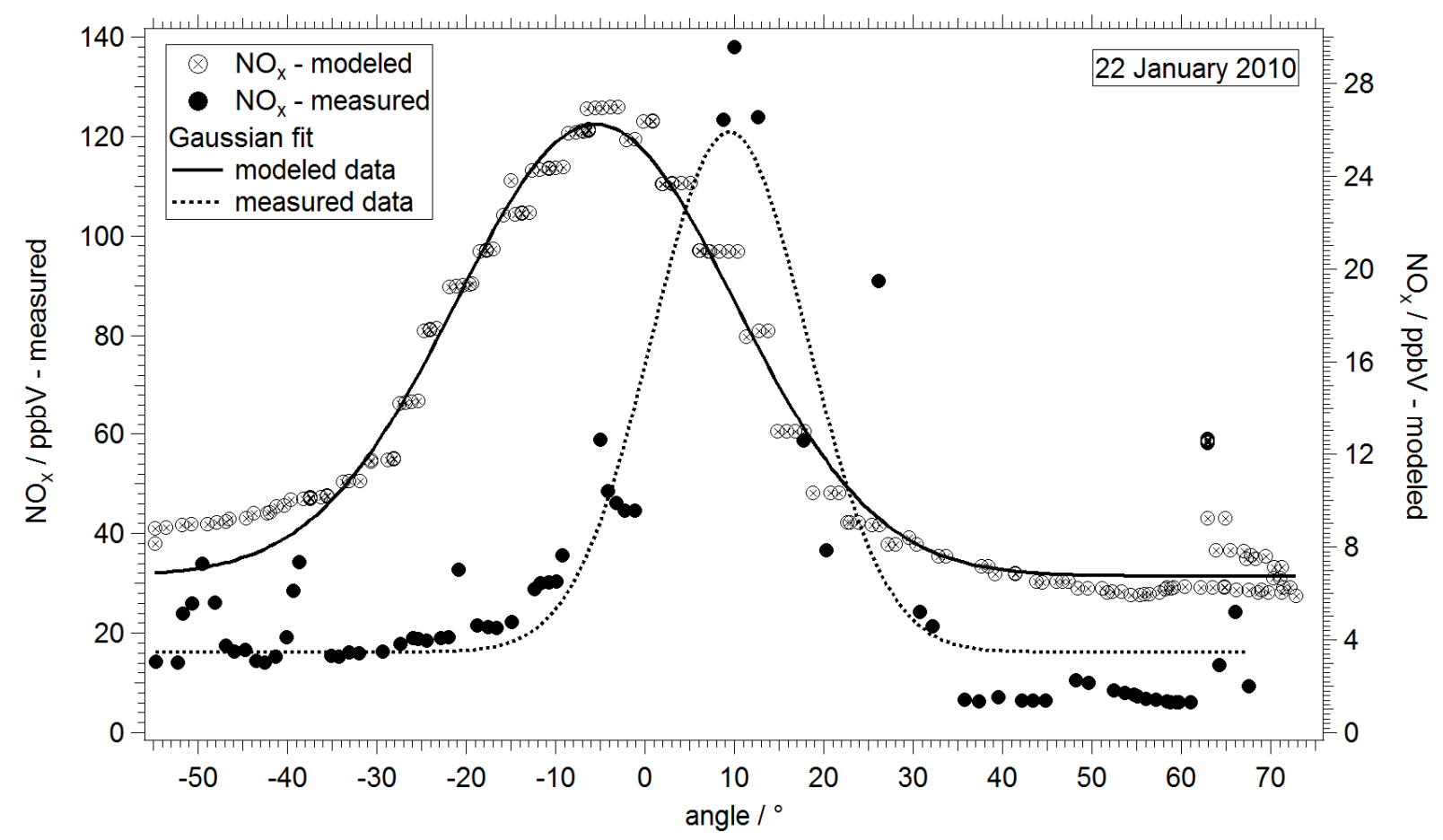

Figure S5. Measured $\mathrm{NO}_{\mathrm{x}}$ (filled circles, left axis) and modeled $\mathrm{NO}_{\mathrm{x}}$ mixing ratios (open circles with crosses, right axis) versus the covered angle related to Paris of a cross section through the emission plume on 22 January 2010. The cross sectional route was in a distance of about $40 \mathrm{~km}$ from the city center. The respective Gaussian fits of the presented data are depicted as solid (for the modeled data) and dashed lines (measured data). The time resolution of all data is $1 \mathrm{~min}$. 


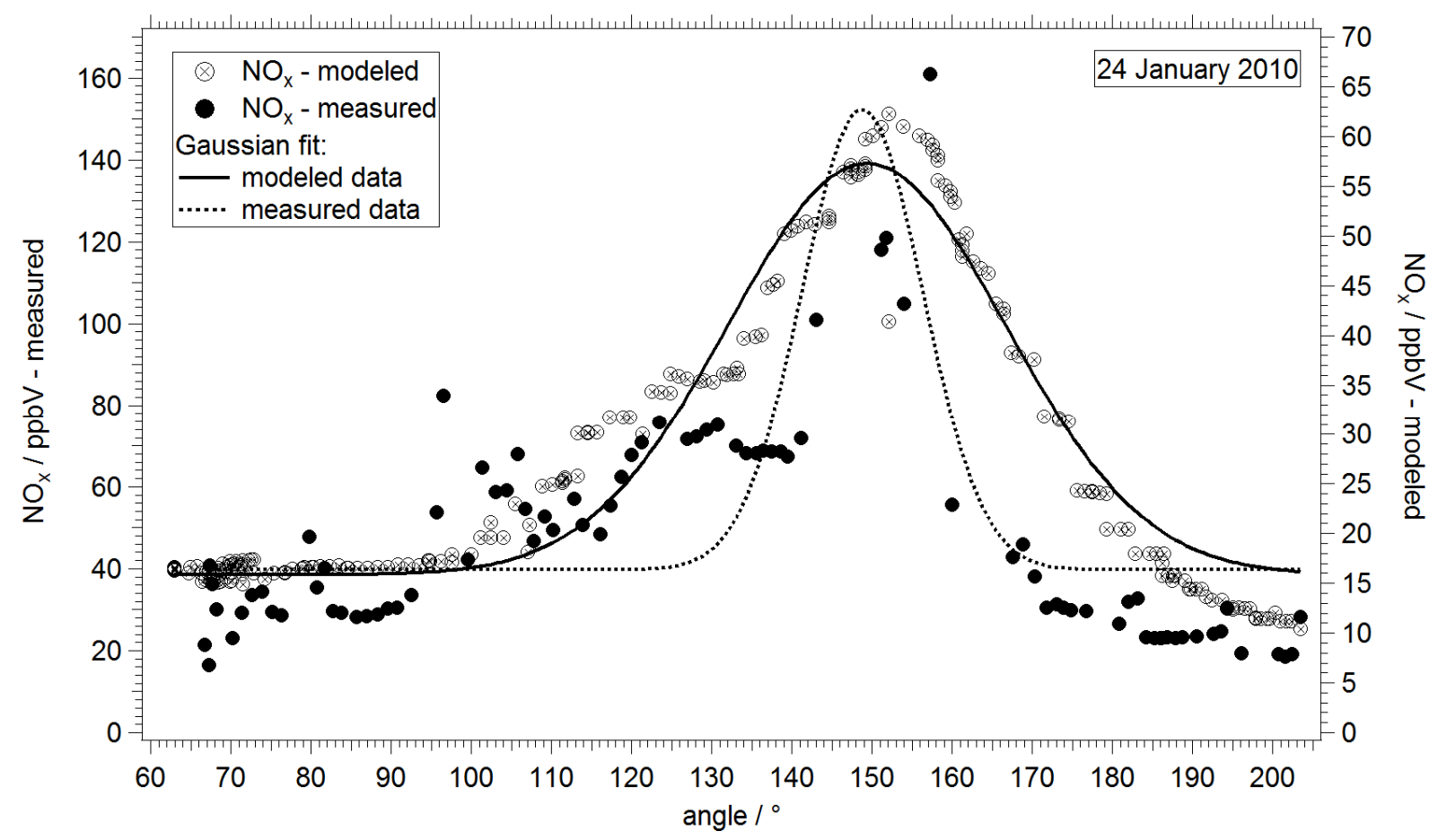

Figure S6. Measured $\mathrm{NO}_{\mathrm{x}}$ (filled circles, left axis) and modeled $\mathrm{NO}_{\mathrm{x}}$ mixing ratios (open circles with crosses, right axis) versus the covered angle related to Paris of a cross section through the emission plume on 24 January 2010. The cross sectional route was in a distance of about $45 \mathrm{~km}$ from the city center. The respective Gaussian fits of the presented data are depicted as solid (for the modeled data) and dashed lines (measured data). The time resolution of all data is $1 \mathrm{~min}$. 


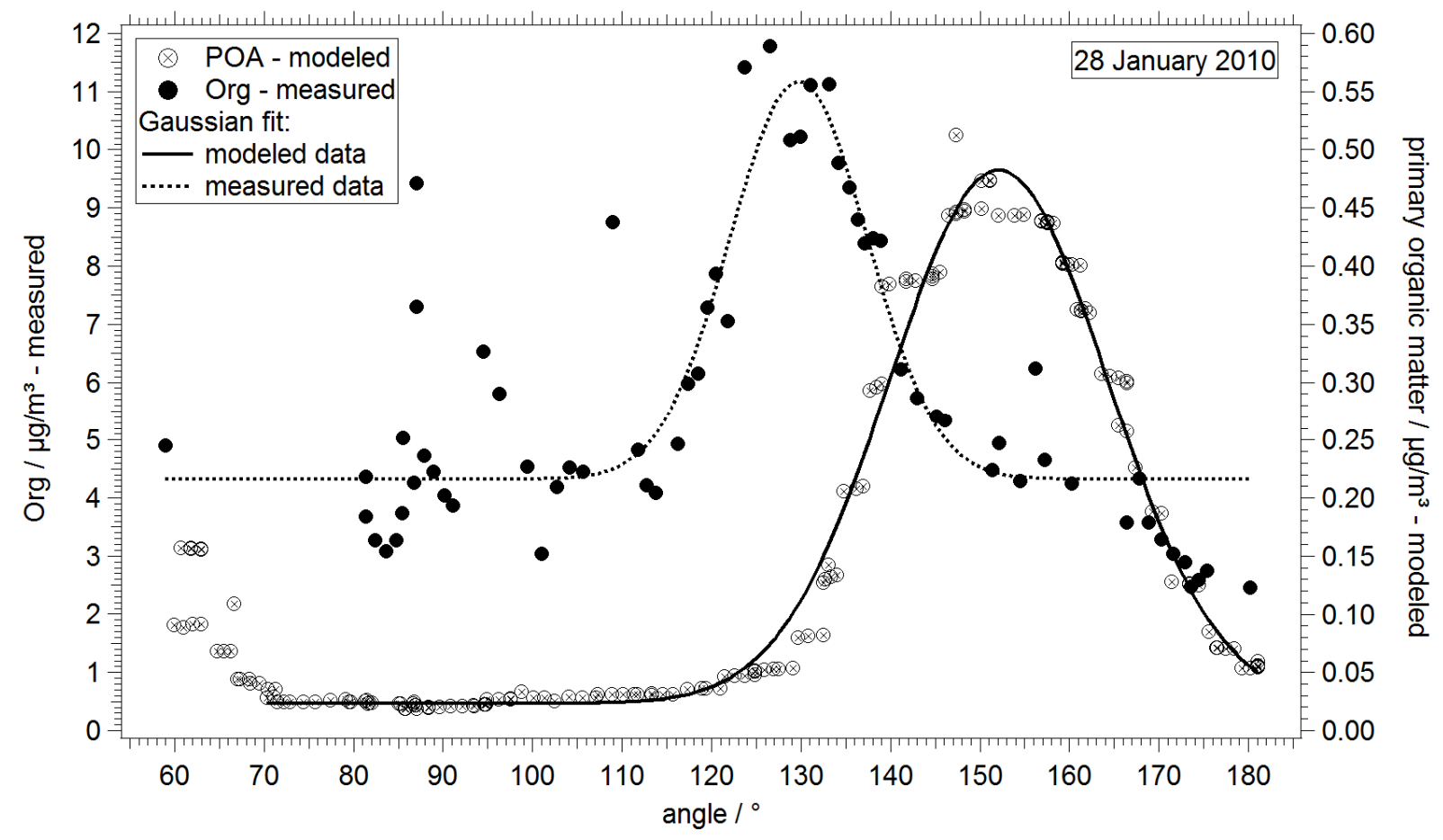

Figure S7. Measured particulate organic matter (filled circles, left axis) and modeled primary organic matter (POA, open circles with crosses, right axis) versus the covered angle related to Paris of a cross section through the emission plume on 28 January 2010. The cross sectional route was in a distance of about $50 \mathrm{~km}$ from the city center. The respective Gaussian fits of the presented data are depicted as solid (for the modeled data) and dashed lines (measured data). The time resolution of all data is $1 \mathrm{~min}$. 


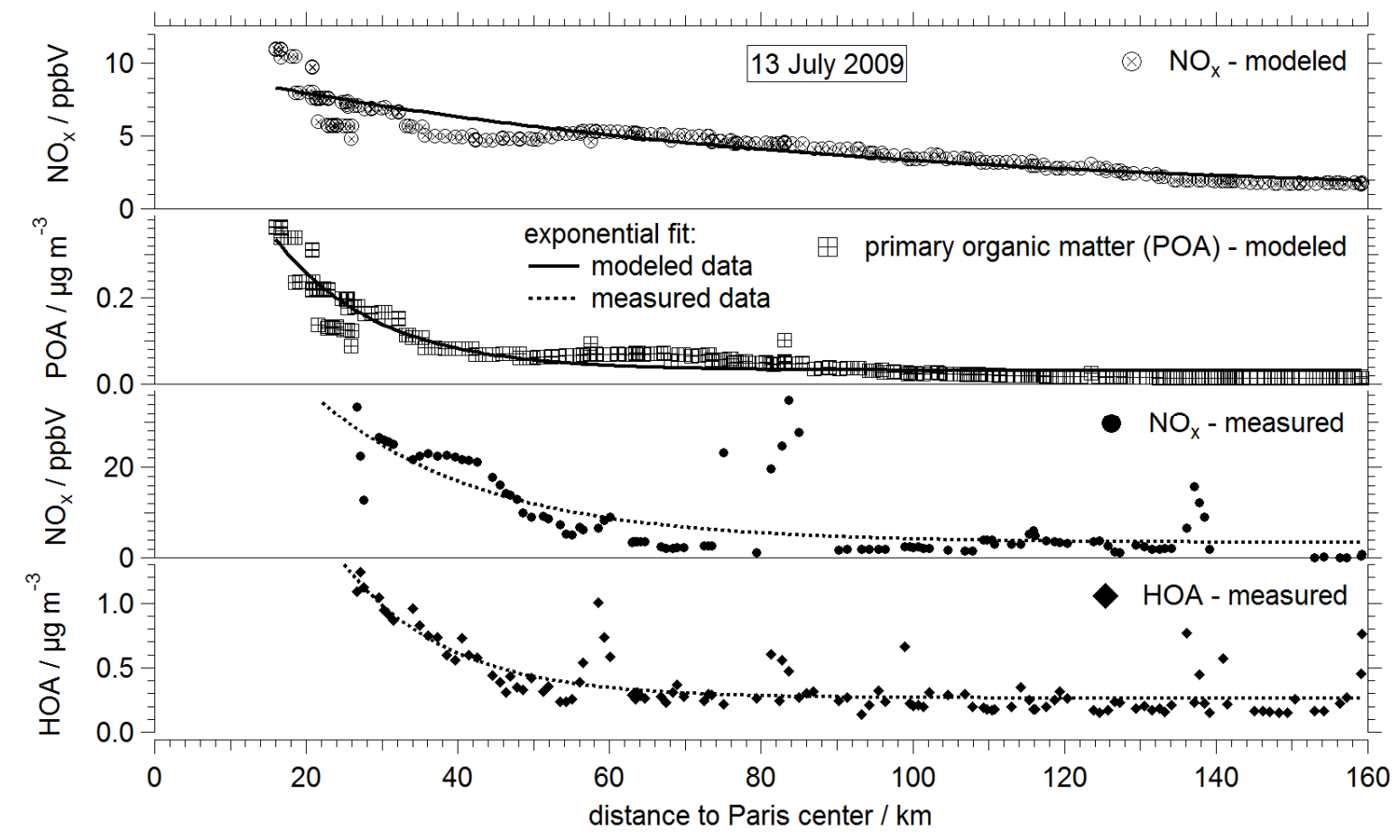

Figure S8. Measured HOA mass concentrations (diamonds) and $\mathrm{NO}_{\mathrm{x}}$ mixing ratios (dots) and modeled primary organic matter mass concentrations (POA, open squares with crosses) and $\mathrm{NO}_{\mathrm{x}}$ mixing ratios (open circles with crosses) versus distance to Paris center from a quasiLagrangian axial measurement on 13 July 2009 (outward trip). The respective exponential fits of the presented data are depicted as solid (modeled) and dashed lines (measured data). The time resolution of all data is $1 \mathrm{~min}$. 


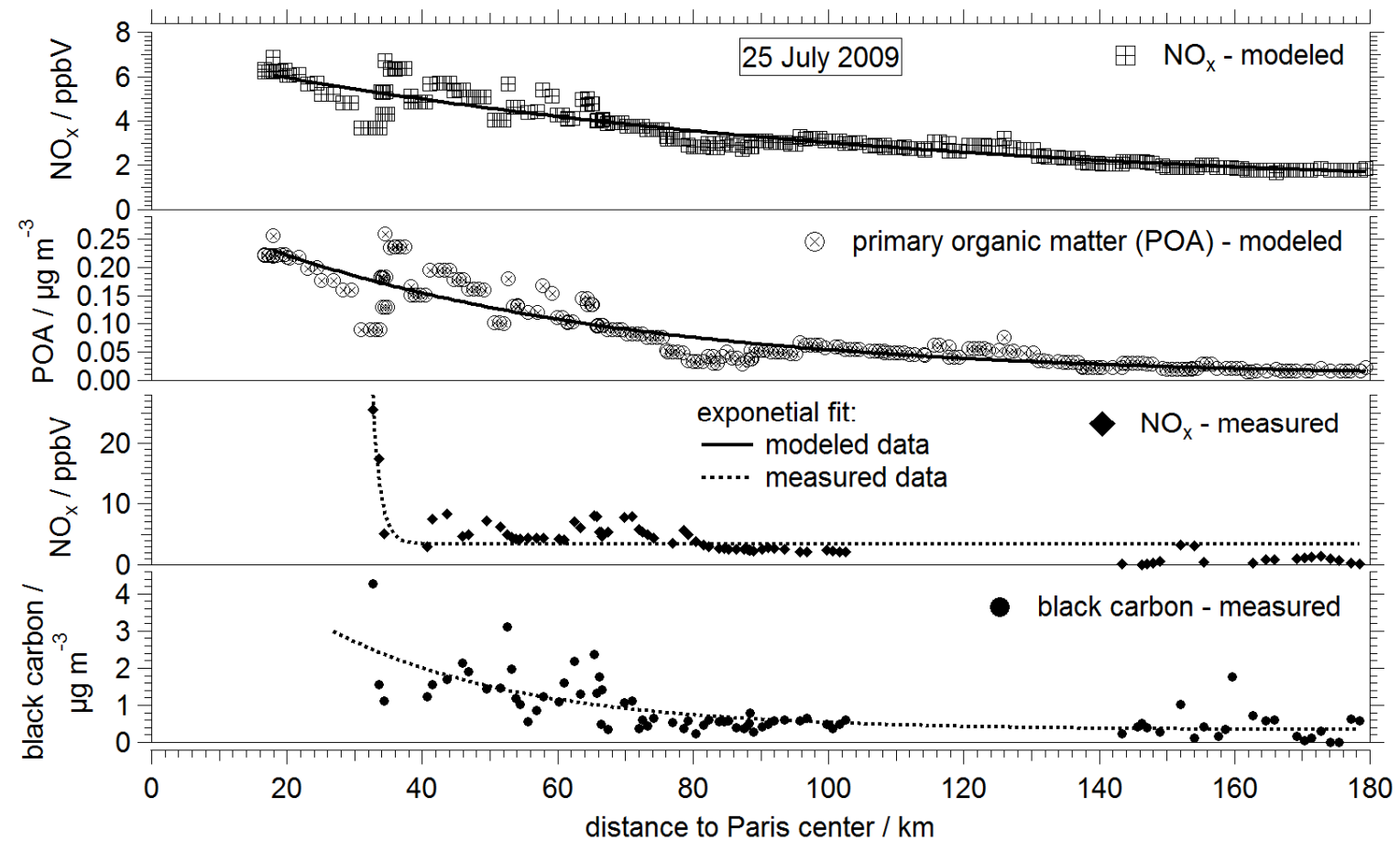

Figure S9. Measured black carbon mass concentrations (dots) and $\mathrm{NO}_{\mathrm{x}}$ mixing ratios (diamonds) and modeled primary organic matter mass concentrations (POA, open circles with crosses) and $\mathrm{NO}_{\mathrm{x}}$ mixing ratios (open squares with crosses) versus distance to Paris center from a quasi-Lagrangian axial measurement on 25 July 2009 (outward trip). The respective exponential fits of the presented data are depicted as solid (modeled) and dashed lines (measured data). The time resolution of all data is $1 \mathrm{~min}$. 


\section{References}

Aiken, A. C., DeCarlo, P. F., Kroll, J. H., Huffman, J. A., Docherty, K. S., Ulbrich, I. M., Mohr, C., Kimmel, J. R., Sueper, D., Sun, Y., Zhang, Q., Trimborn, A., Northway, M., Ziemann, P. J., Canagaratna, M. R., Onasch, T. B., Alfarra, M. R., Prévôt, A. S. H., Dommen, J., Duplissy, J., Metzger, A., Baltensperger, U., and Jimenez, J. L.: O/C and OM/OC Ratios of Primary, Secondary, and Ambient Organic Aerosols with High-Resolution Time-of-Flight Aerosol Mass Spectrometry, Environ. Sci. Technol., 42, 4478-4485, doi:10.1021/es703009q, 2008.

Alfarra, M. R., Prévôt, A. S. H., Szidat, S., Sandradewi, J., Weimer, S., Lanz, V. A., Schreiber, D., Mohr, M., and Baltensperger, U.: Identification of the mass spectral signature of organic aerosol from wood burning emissions, Environ. Sci. Technol., 41, 5770-5777, doi:10.1021/es062289b, 2007.

Allan, J. D., Williams, P. I., Morgan, W. T., Martin, C. L., Flynn, M. J., Lee, J., Nemitz, E., Phillips, G. J., Gallagher, M. W., and Coe, H.: Contributions from transport, solid fuel burning and cooking to primary organic aerosols in two UK cities, Atmos. Chem. Phys., 10, 647-668, doi:10.5194/acp-10-647-2010, 2010.

AMS Spectral Database: AMS Spectral Database, available at: http://cires.colorado.edu/jimenez-group/AMSsd/ (last access: 11 December 2013), 2013.

Beekmann, M., Prévôt, A. S. H., Drewnick, F., Sciare, J., Pandis, S. N., van der Gon, H. A. C. D., Crippa, M., Freutel, F., Poulain, L., Ghersi, V., Rodriguez, E., Beirle, S., Zotter, P., von der Weiden-Reinmüller, S.-L., Bressi, M., Fountoukis, C., Petetin, H., Szidat, S., Schneider, J., Rosso, A., El Haddad, I., Megaritis, A., Zhang, Q., Slowik, J. G., Moukhtar, S., Kolmonen, P., Stohl, A., Eckhardt, S., Borbon, A., Gros, V., Marchand, N., Jaffrezo, J. L., Schwarzenboeck, A., Colomb, A., Wiedensohler, A., Borrmann, S., Lawrence, M., Baklanov, A. und Baltensperger, U.: Regional emissions control fine particulate matter levels in the Paris Megacity, in preparation for Atmos. Chem. Phys. Discuss., 2014.

Crippa, M., DeCarlo, P. F., Slowik, J. G., Mohr, C., Heringa, M. F., Chirico, R., Poulain, L., Freutel, F., Sciare, J., Cozic, J., Di Marco, C. F., Elsasser, M., Nicolas, J. B., Marchand, N., Abidi, E., Wiedensohler, A., Drewnick, F., Schneider, J., Borrmann, S., Nemitz, E., 
Zimmermann, R., Jaffrezo, J.-L., Prévôt, A. S. H., and Baltensperger, U.: Wintertime aerosol chemical composition and source apportionment of the organic fraction in the metropolitan area of Paris, Atmos. Chem. Phys., 13, 961-981, doi:10.5194/acp-13-961-2013, 2013.

Freutel, F., Schneider, J., Drewnick, F., von der Weiden-Reinmüller, S.-L., Crippa, M., Prévôt, A. S. H., Baltensperger, U., Poulain, L., Wiedensohler, A., Sciare, J., Sarda-Estève, R., Burkhart, J. F., Eckhardt, S., Stohl, A., Gros, V., Colomb, A., Michoud, V., Doussin, J. F., Borbon, A., Haeffelin, M., Morille, Y., Beekmann, M., and Borrmann, S.: Aerosol particle measurements at three stationary sites in the megacity of Paris during summer 2009: Meteorology and air mass origin dominate aerosol particle composition and size distribution, Atmos. Chem. Phys., 13, 933-959, doi:10.5194/acp-13-933-2013, 2013.

He, L.-Y., Lin, Y., Huang, X.-F., Guo, S., Xue, L., Su, Q., Hu, M., Luan, S.-J., and Zhang, Y.-H.: Characterization of high-resolution aerosol mass spectra of primary organic aerosol emissions from Chinese cooking and biomass burning, Atmos. Chem. Phys., 10, 1153511543, doi:10.5194/acp-10-11535-2010, 2010.

Schauer, J. J., Rogge, W. F., Hildemann, L. M., Mazurek, M. A., and Cass, G. R.: Source apportionment of airborne particulate matter using organic compounds as tracers, Atmos. Env., 30, 3837-3855, doi:10.1016/j.atmosenv.2007.10.069, 1996.

Schneider, J., Weimer, S., Drewnick, F., Borrmann, S., Helas, G., Gwaze, P., Schmid, O., Andreae, M. O., and Kirchner, U.: Mass spectrometric analysis and aerodynamic properties of various types of combustion-related aerosol particles, Int. J. Mass Spectrom., 258, 37-49, doi:10.1016/j.ijms.2006.07.008, 2006.

Zhang, Q. J., Beekmann, M., Drewnick, F., Freutel, F., Schneider, J., Crippa, M., Prévôt, A. S. H., Baltensperger, U., Poulain, L., Wiedensohler, A., Sciare, J., Gros, V., Borbon, A., Colomb, A., Michoud, V., Doussin, J.-F., Denier van der Gon, H. A. C., Haeffelin, M., Dupont, J.-C., Siour, G., Petetin, H., Bessagnet, B., Pandis, S. N., Hodzic, A., Sanchez, O., Honoré, C., and Perrussel, O.: Formation of organic aerosol in the Paris region during the MEGAPOLI summer campaign: evaluation of the volatility-basis-set approach within the CHIMERE model, Atmos. Chem. Phys., 13, 5767-5790, doi:10.5194/acp-13-5767-2013, 2013. 